\title{
PREVALENCE OF INTESTINAL HELMINTH PARASITES OF CHICKEN (Gallus gallus domesticus Linnaeus, 1758) IN LALITPUR DISTRICT, NEPAL
}

\author{
Janak Raj Subedi* \\ Tasneem Mujahid \\ Bijay Cheetri
}

\section{ABSTRACT}

This study was aimed to determine the prevalence of intestinal helminth parasites of local chicken (Gallus gallus domesticus) from Lalitpur district, Nepal. It was carried out from February 2014 to March 2015. A total of 125 samples (93 alimentary canals of freshly killed chicken and 32 stool samples from ground and fowl runs) were collected. Out of 93 alimentary canals 17 were collected from free range chicken and 76 were from slaughtered house i.e. from poultry farm chicken. The faecal samples were collected in the sterile vials containing 2.5 percent potassium dichromate. Depending upon the convenience, post mortem examination method, differential floatation method and direct smear method were used for the examination of samples. The present study showed only 40 percent of all the poultry examined as infected. Overall 5 species of nematodes, 1 species of cestode and 4 unidentified species were found to be prevalent in chicken from Lalitpur district. The highest prevalence rate was found with Heterakis gallinarum (22.4\%) followed by Capillaria species (16\%), Ascaridia galli (10.4\%), unidentified species (4.8\%) and Raillietina tetragona (4\%). Statistically there was a significant difference in the prevalence of helminth species $\left(\chi^{2}=33.83 ; p<0.05 ; \alpha=1\right)$. Likewise, there was significant difference in the prevalence rate of helminth parasites in free range chicken and poultry chicken $\left(\chi^{2}=22.055 ; p<0.05 ; \alpha=1\right)$.

Keywords: Chicken, Nematode, Cestode, Lalitpur, Helminth

\section{INTRODUCTION}

A domestic fowl or chicken (Gallus gallus domesticus), belonging to the family Phasianidae, is a sub species of Red Jungle Fowl. It is one of the most common and widespread domestic animals, with a total population

* Mr. Subedi is a Lecturer, Central Department of Zoology, Kirtipur, TU. Mujahid and Chhetri are associated with Central Department of Zoology, Kirtipur. TU. 
of more than 19 billion as of 2011 (UNFAO, 2011). It is one of the most common and domesticated birds than any other species in the world. Human keep chickens primarily as a source of food, consuming both their meat and their eggs (UNFAO, 2011). Parasitic infection in chicken is the major problem in Nepal which leads to economic loss of the country. Domestic fowls are more often infected due to unhygienic management practices, malnutrition, lack of veterinary supervision and also the complicated life cycle of the parasites (Nair and Nadakal, 1981). Chicken infected with parasites show retarded growth, decreased egg production, reduced weight gain, significant haemoglobin depression (Nair and Nadakal, 1981), villous atropy, catarrhal enteritis, granuloma formation in duodenum, desquamation of villi and submucosal glands congestion, inflammatory reaction and vacuolation of epithelial cells (Kurkure and Ganorkar 1998).

Parasitism is an association in which the parasite is metabolically dependent to a greater or lesser extent to the host. Gastro- intestinal parasites are however the most prevalent and most devastating parasites affecting chicken productivity (Swaton et al., 2003). According to and village chicken are raised mainly under the free range (scavenging) product system, with partial or no housing and this predisposes the chicken to disease and parasites especially helminths (Muchadeyi et al., 2004; Mwale and Masika, 2009 and Swaton et al., 2003). In village, chicken are raised mainly under the free range (scavenging) with partial or no housing and this predisposes the chicken to disease and parasites especially helminths (Muchadeyi et al., 2004; Mwale and Masika, 2009 and Swaton et al., 2003). Different types of helminth parasites infect the chicken flocks. Worms find cozy places to stay in the crop, gizzard, intestine, caecum, windpipe and even the eyelids (Gauthier and Ludlow, 2013). On the basis of their site of location helminths are of different types, the worm which are found in caecum of large intestine are called caecal worms (Heterakis SPP.), worms which are found in eye are called eye worm (Oxyspirura mansoni ), Gape worms are found in trachea (Syngamus trachea) (Gauthier and Ludlow, 2013). These worms are also called "red- worm" or "forked-worm" and birds infected with gape worm show "open mouth breathing characteristics". Round worm (Ascaridia) and tape worms (Raillietina) are found in intestine while thread worm (Capillaria) is found in crop or oesophagus (Janquera, 2017). The eggs and immature stages of many parasitic worms can live outside of the chicken host for a long time, possibly several years, whereas some parasitic worms spend part of their life cycle in other creatures such as 
earthworms, insects, slugs or snails. Chicken pick up worms by eating dirt or litter contaminated with worms eggs or by eating small creatures carrying immature stages of worm (Janquera, 2017).

\section{STUDY AREA}

The study was carried out in Lalitpur Sub Metropolitan city which is one of the major cities of Nepal located in the south- central part of Kathmandu valley. It is best known for its rich cultural heritage particularly its tradition of arts and crafts. At the time of 2011 Nepal census it had a population of 226728 in 54748 individual households. The city has an area of $15.43 \mathrm{sq} . \mathrm{km}$ and is divided into 22 municipal wards. It is situated at $27^{\circ}$ $40^{\prime} \mathrm{N}, 85^{\circ} 19^{\prime} \mathrm{E} / 27.66^{\circ}, 85.317^{\circ} \mathrm{E}$. Climate of this area is with relatively high temperature and evenly distributed precipitation throughout the year. There are total 272655 number of chicken domesticated in Lalitpur district. Out of these chicken 60,000 are reared in backyard and 212,655 are reared commercially as poultry farming (FAO, 2014).

Figure 1: Lalitpur District.

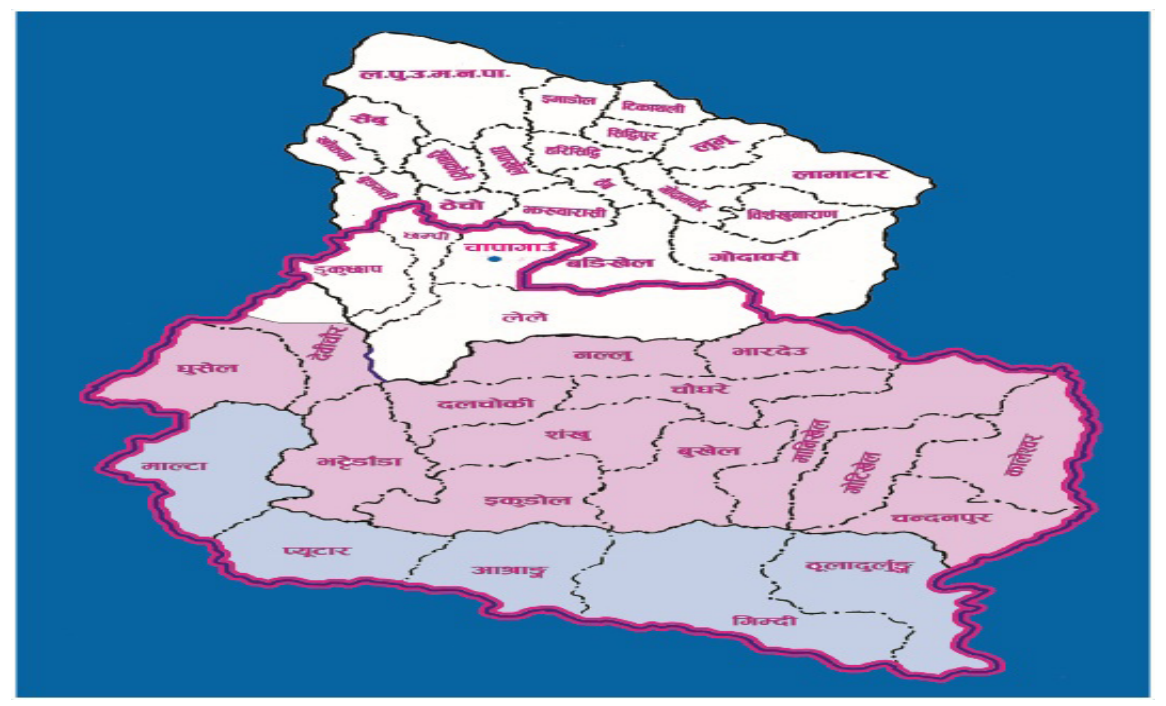

\section{MATERIAL AND METHODS}

\section{Sample Collection Preservation and Examination}

A total of 125 samples (93 alimentary canals of freshly killed chicken and 32 stool samples from ground and fowl runs) were collected 
from Lalitpur District. Out of 93 alimentary canals 17 were collected from free range chicken and 76 were from slaughtered house i.e. from poultry farm chicken. These samples were collected from different places of Lalitpur district from February 2014 to March 2015. The faecal sample were collected in the sterile vials containing $2.5 \%$ potassium dichromate with the help of wooden stick. Potassium dichromate was used as preservative that helped to maintain the morphology of eggs and also prevented further development of helminth eggs. The alimentary canal were collected in polythene bag and were immediately brought to the laboratory for the examination. (Gurung, 2016). Depending upon the convenience, post mortem examination method, differential floatation method and direct smear method were used for the examination of sample. For post mortem examination method The alimentary canal of chicken was cut longitudinally from oesophagus to rectum including both caecal tubes. All worms visible to necked eye were removed using thumb forceps and brush (Fowler, 1990). Cestodes were whole mounted for identification while nematode were fixed in glycerol jelly and observed under the microscope. The freshly collected helminths parasites were kept in normal saline before fixation. Permanent slides (whole mount slides) of parasites were prepared for their identification according to the method described by Cable (1957).

For differential floatation method The saturated salt solution of specific gravity 1.2 was prepared by allowing an excess of common salt to boil in a basin until a scum was formed on the surface. It was cooled and stored in a bottle leaving an excess of undissolved salt at the bottom. Four gram of fecal material was taken in a test tube and a few drops salt solution was added (Hansen and Perry, 1994). It was then stirred with a glass rod or a small piece of stick so as to make an even emulsion. After that more salt solution (15 to $20 \mathrm{ml}$ according to the capacity of the test tube used) was added till the test tube was nearly full, stirring was continued through the process. Any coarse matter, which float up, were removed without fear of removing any egg, as egg takes a long time (20 to 30 minutes) to come to the surface of the fluid. At this stage the test tube was placed on the level surface and the final filling of the test tube was done by means of a dropper until a convex meniscus was formed. A glass slide was carefully laid on the top of the test tube so that its center is in contact with the fluid. The preparation was allowed to stand for 20 to 30 minutes, after which the glass slide was quickly lifted, turned over smoothly so as to avoid spilling of the liquid and was examined under the microscope (Chatterji, 2009). 
For direct smear method method small amount of feces was placed on a slide . A drop of normal saline or Lugol's solution was added to the feces and mixed thoroughly. Since we were looking for the helminth eggs , larva and cysts Lugol's solution or normal saline was used. Then the fecal materials were covered with cover slip. The cover slip was moved around until it laid flat. The smear film was made thin so that the light from the microscope was able to pass through the sample in order for us to examine it. The slides were examined at 10X and 40X objective lens. (Chatterji, 2009).

\section{Statistical Analysis}

Prevalence of infection of identified species in each area was calculated as the number of individual chicken infected by a specific helminth species at the time of study was divided by the total number of chicken examined and multiplied by 100 . Variation in the prevalence of gastrointestinal helminths in relation to helminth species and chicken type were analysed by using Chi- square statistics. In all cases $\mathrm{p} \chi 0.05$ was considered indicative of statistically significant difference or association.

\section{RESULTS AND DISCUSSION}

The present study revealed that $40 \%$ among all poultry examined were infected by one or more species of helminth parasites. 36 intestine of chicken out of 93 were infected with helminth parasites while 14 stool samples or droppings were found positive for helminth eggs.

\section{Prevalence Rate on the Basis of Species}

The highest prevalence of Heterakis gallinarum (22.4\%) was seen followed by Capillaria species (16\%), Ascaridia galli (10.4\%), and Raillietina tetragona (4\%). Similarly the prevalence of unidentified species was found $4.8 \%$. Statistically, there was a significant difference in the prevalence of helminth species $\left(\chi^{2}=33.832, \mathrm{p}<0.05\right)$ with the highest prevalence of $H$. gallinarum.

Table 1: Species- wise Prevalence Rate $(\%), n=125$

\begin{tabular}{|l|l|l|l|l|}
\hline Name of Parasite & \multicolumn{2}{|l|}{ No. of Chicken Infected by } & T & $\begin{array}{l}\text { Prevalence } \\
\text { Rate }\end{array}$ \\
\hline \multirow{2}{*}{ Ascaridia galli } & Adult & Egg & 13 & $10.40 \%$ \\
\cline { 2 - 5 } & 9 & 4 & & \\
\hline Heterakis gallinarum & 23 & 5 & 28 & $22.40 \%$ \\
\hline Capillaria SPP. & 17 & 3 & 20 & $16 \%$ \\
\hline Raillietina tetragona & 5 & 0 & 5 & $4 \%$ \\
\hline Unidentified & 4 & 2 & 6 & $4.80 \%$ \\
\hline
\end{tabular}

where, $\mathrm{t}=$ total no. of infected chicken, Prevalence Rate $=(\mathrm{t} / \mathrm{n}) \times 100 \%$, $\mathrm{n}=125$. 


\section{Prevalence Rate on the Basis of Class}

Table 2: Class- wise Prevalence Rate (\%), $n=125$

\begin{tabular}{|l|l|l|}
\hline Name of class & $\mathbf{t}$ & Prevalence rate \\
\hline Nematoda & 61 & $48.80 \%$ \\
\hline Trematoda & 5 & $4 \%$ \\
\hline Cestoda & 0 & $0 \%$ \\
\hline Unidentified & 6 & $4.80 \%$ \\
\hline
\end{tabular}

where, $\mathrm{t}=$ total no. of infected chicken, Prevalence rate $=(\mathrm{t} / \mathrm{n}) \times 100 \%$, $\mathrm{n}=125$.

\section{Prevalence Rate on the Basis of Chicken Type}

Out of 40 samples examined from free range chicken, 28 were found to be infected with the prevalence rate of $70 \%$ while from 85 samples of poultry chicken (from slaughtered house), 22 were infected with the prevalence rate of $25.88 \%$. Statistically there was significant difference in the prevalence rate of helminth in free range chicken and poultry chicken $(\chi 2=22.055, \mathrm{p}<0.05, \alpha=1)$.

Figure 2: Prevalence on the Basis of Chicken Type.

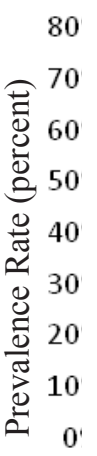

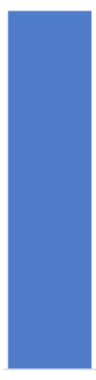

Free range chicken

Poultry chicken

Types of chicken

The domestic fowl or chicken harbours many intestinal parasites due to its feeding habit .According to Muchadeyi et al. (2004) and Mwale and Masike (2009) village chicken which are raised mainly under the free range (scavenging) product system, with partial or no housing have higher rate of infection of disease and parasites especially helminthes (Swaton 
et al., 2003). Likewise, Mwale and Masike (2011) reported that village chickens increase rural farmers' nutritional and income status. Nonetheless, chicken productivity is chiefly affected by gastro-intestinal parasites and there is dearth of information on the prevalence of these parasites in village chickens in South Africa.

The study showed $40 \%$ among all poultry examined were infected by one or more species of helminth parasites which agrees with the work of Sudhir (2013) who found 51.67\% infection in free range chicken in India. The present study is also more or less similar to the report of other worker who reported the prevalence rate of $41.4 \%$ (Tesfaheyawet et al., 2010), 53.00\% (Matur et al., 2010) and 37.9\% (Dawet et al., 2012). In the present study six species of helminth were identified comprising five nematodes and one cestode compared to seven species of helminth identified by Adang et al., (2014) comprising of six cestodes and one nematode, five species by Kose et al. (2009) comprising four nematodes and one cestodes, five species by Rayyan et al., (2010) comprising of three nematodes and two cestodes and three species by Matur (2002) comprising two cestodes and one nematode

Out of 40 samples examined from free range chicken, 28 were found to be infected with the prevalence rate of $70 \%$ while 85 samples of poultry farm chicken (from slaughtered house) were found to have prevalence rate of 25.88\% which agrees with the work of Hamad (2013) and Yoriyo et al. (2005). Similarly, Mikail and Adamu (2008) reported high infection rate in free range chicken $(92.66 \%)$.

Statistically there was a significant difference in the prevalence rate of helminth in free range chicken and poultry chicken $(p<0.05)$. This may be because the free range chicken or backyard poultry are more susceptible to parasitic infection. The main food of backyard chicken consists of different types of seeds, kitchen wastage, insects, slugs, earthworm, etc. insects slugs worms act as intermediate host of many bioparasites (Soulsby, 1982).

\section{CONCLUSION}

The study was carried out to find the prevalence of intestine helminth parasites of local chicken in Lalitpur district. A total of 93 intestine and 32 stool sample of local chicken, Gallus gallus domesticus, were collected from different places of Lalitpur district. The collected samples were examined thoroughly for the presence of helminth parasites in the form of adult or egg. The present study showed that only $40 \%$ of all the poultry examined were 
infected. The highest prevalence rate was found with Heterakis gallinarum (22.4\%) followed by Capillaria species (16\%), Ascaridia galli (10.4\%) and Raillietina tetragona (4\%). Similarly the prevalence of unidentified species was $(4.8 \%)$.

The infection was more in free range chicken (70\%) as they are reared in unhygienic environment and are more susceptible to parasitic infection due to their feeding habit. The intestine which were collected from slaughter house were with least infection (25.88\%) as they were bought from poultry farm where chicken are reared in hygienic environment with medication.

\section{ACKNOWLEDGEMENTS}

We acknowledge gratitude to Assoc. Prof. Dr. Mahendra Maharjan for his assistance in the research work. Thanks to Heads of Central Departments of Zoology and Environmental Science for providing necessary facilities in lab. We are also grateful to all the teaching and non-teaching staffs of Central Department of Zoology

\section{REFERENCES}

Adang, K.C., Asher, R., \& Abba, R. (2014). Gastro-intestinal helminth of domestic chicken Gallus gallus domesticus and duck Anas platyrhynchos slaughtered at Gombe main market, Gombe State, Nigeria. Asian Journal of Poultry Science, 8(2): 32-40.

Cable, R.M. (1957). An illustrated laboratory manual of parasitology. 4th Edition. Burgess Publishing Co. 426, South Sixth Street, Minneapolis 15, Minnesota Chatterjee.

Chatterjee, K. D. 2009. Parasitology: Protozoology and Helminthology. 13th ed. CBS publishers. pp. 260-266.

Dawet, A., Yakubu, D.P., Dung, J.P., \&Daburum, Y.H. (2012). Gastrointestinal helminthes of domestic fowl in Jos, Plateau State, Nigeria. Nigerian Journal of Parasitology, 33(1): 85 -89.

FAO, (2014). Food and Agriculture Organization of United Nation. FAO animal production and health livestock country reviews. In Poultry sector of Nepal, Shrestha, K.B. (ed.). No. 8. Rome. pp. 1-52.

Fowler, N.G. (1990). How to carry out a field investigation. In poultry diseases. 2nd Edition, Bailliere, Tindall. pp. 370-400. 
Gauthier, J. \& Ludlow, R. (2013). Chicken health for dummies. $1^{\text {st }}$ ed. pp. 336.

Gurung, A. (2016). Prevalence of gastrointestinal parasites of pigeon (Columba sp. Linnaeus 1758) in three temples of Pokhara valley. M. Sc. Thesis. Central Department of Zoology, Tribhuvan University, Kathmandu, Nepal.

Hamad, H.A. (2013). Helminth Parasites in the Intestinal Tract of Indigenous Chicken in Jordanian Villages. Pakistan Journal of Nutrition, 12(3): 209-212.

Hensel, J. \& Perry, B. (1994). Techniques for parasites assays and identification in fecal samples. In management of vertisols in SubSaharan Africa, 39: 77-92.

Janquera, P. (2017). Parasites of dogs, cats, horses and livestock: Biology and control. Parasitipedia.net.

Kose, M., Sevimli, F.K., Kozan, E.K. \& Cicek, H.S.( 2009). Prevalence of gastrointestinal helminthes in chickens in Afyonkazahisar district, Turkey. Kafkas Univ. Vet., 15: 411-416.

Kurkure, N.V. \& Ganorkar, A.G. (1998). Bilateral simonoma in a duck (Anas platyrhynchus). Avian Pathology, 27: 644-645.

Matur, B.M., (2002). Prevalence of some gastrointestinal parasites in pullets of chickens (Gallus gallus domestica) in the Federal Capital Territory Abuja. J. Trop. Biosci., 2: 78-82.

Matur, B.M., Dawam, N.N. \& Malann, Y.D. (2010). Gastrointestinal helminth parasites of local and exotic cicken slaughtered in Gwangwalada, Abuja (FCT), Nigeria. N.Y. Science Journal, 3: 96-99.

Mikail, H.G.\& Adamu,Y.A. (2008). A survey of the gastro-intestinal helminthes of chicken in Sokoto Metropolis, Nigeria. Nigerian Veterinary Journal, 29(11): 72-75.

Muchadeyi, F.C., Sibanda, S., Kusina, N.T., Kusina, J. \& Makuza, S. (2004). The village chicken production system in Rushinga District of Zimbabwe, 16(6): 154-158.

Mwale, M. \& Masika, P.J. (2009). Ethno-veterinary control of parasites, management and role of village chicken in rural household of Centage district in the Eastern Cape, South Africa. 41: 1685-1693. 
Mwale, M. \& Masika, P.J. (2011). Point prevalence study of gastro-intestinal parasites in village chickens of Centane district, South Africa. 6(9): 2033-2038.

Nair, V.K. \& Nadakal, A.M. (1981). Haematological changes in domestic fowl experimentally infected with the cestode (Raillietina tetrogona Molin, 1858). Veterinary Parasitol, 81: 49-58.

Rayyan,A.,Ai-Hindi,A. \&Al-Zain, B. (2010). Occurrence of gastrointestinal helminth in commercial and free-range chickens in Gaza strip, Palestine. Egypt Poultry Science, 30: 601-606.

Soulsby, E.J.L.(1982). Helminths, Arthropods and Protozoa of Domesticated Animals. $7^{\text {th }}$ Edition, Baillere Tindal, London, pp.763-777.

Soulsby, E.J.L.(1982). Helminths, Arthropods and Protozoa of Domesticated Animals. 7th Edition, Baillere Tindal, London, pp.763-777.

Sudhir, T.N. (2013). Studies on the prevalence of helminth infection in broiler poultry birds from Marathwada Region, (MS) India, Science Research Reporter, 3(2): 233-238.

Swaton, H.K., Tshovhote, J., Nesamvumi, E., Ranwedzi, N.N. and Fouric, C. (2003).Characterization of indigenous free ranging poultry production system under traditional management conditions in the Vhembe district of the Limpopo Province, South Africa.

Tesfaheyawet, Z., Amare, E. \& Hailu, Z. (2012). Helminthosis in chickens in selected small scale commercial poultry farm in and around Wozeda, Southeastern Ethiopia, 2(9): 462-468.

United Nation's Food \& Agriculture Organisation(UNFAO). (2011). “Global Livestock Counts". The Economist.

Yoriyo, K.P., Rabiyi, J.P., Panda, S.M. \& Adamu, S.U. (2005). Intensities of helminth parasites of free range chickens in bauchi and environs. Yankari J., 2: 135-139. 